\title{
Adenoid cystic carcinoma of the prostate: an unusual subtype of prostate cancer
}

\author{
Pramod Kumar Julka,,*, Amit Verma ${ }^{2, *}$, Sanjay Gupta ${ }^{3}$, Kush Gupta $^{3}$, Rahul Rathod ${ }^{4}$ \\ 'Department of Medical Oncology, Max Institute of Cancer Care, New Delhi 110024, India. \\ 2Department of Molecular Oncology, Max Institute of Cancer Care, New Delhi 110024, India. \\ ${ }^{3}$ Department of Clinical Operations, Catalyst Clinical Services Pvt. Ltd., New Delhi 110089, India. \\ ${ }^{4}$ Department of Medical Affairs, MitraRxDx India Pvt. Ltd, Bengaluru 560037, India. \\ ${ }^{\star}$ Equal contribution.
}

Correspondence to: Dr. Pramod Kumar Julka, Department of Medical Oncology, Max Institute of Cancer Care, Lajpat Nagar, New Delhi 110024, India. E-mail: pkjulka18@yahoo.co.in; Dr. Amit Verma, Department of Molecular Oncology, Max Institute of Cancer Care, New Delhi 110024, India. E-mail: amitverma.dr@gmail.com

\begin{abstract}
How to cite this article: Julka PK, Verma A, Gupta S, Gupta K, Rathod R. Adenoid cystic carcinoma of the prostate: an unusual subtype of prostate cancer. J Trans/ Genet Genom 2020;4:455-63. http://dx.doi.org/10.20517/jtgg.2020.46
\end{abstract}

Received: 10 Sep 2020 First Decision: 9 Oct 2020 Revised: 15 Oct 2020 Accepted: 3 Nov 2020 Available online: 13 Nov 2020

Academic Editor: Sanjay Gupta Copy Editor: Cai-Hong Wang Production Editor: Jing Yu

\begin{abstract}
Adenoid cystic carcinoma (ACC) of the prostate is an extremely rare disease that arises from the basal cells of prostate acini and presents a poor prognosis for metastatic cases. Multiple treatment options exist for different stages of prostate cancer that include prostatectomy, radiation therapy, chemotherapy, and hormone therapy with gonadrotropin-releasing hormone $(\mathrm{GnRH})$ agonists and antagonists for androgen receptor (AR)-positive cases. Although ACC has a biological potential that allows metastasis in a few cases; the current treatment option consists primarily of surgical resection along with close, long-term follow-up. Herein, we report this rare entity in a 79-year-old man who presented with liver metastasis. The tumor expressed GnRH receptor (GnRHR) and a very low level of Programmed death-ligand 1 (PD-L1). Immunohistochemical analysis revealed that the primary tumor was highly proliferative and AR-negative. We employed a clinically validated technology that utilizes patient's tumor and blood to recreate the tumor microenvironment ex vivo. After the diagnosis, we used the platform to test the efficacy of degarelix (a GnRHR antagonist), atezolizumab (a PD-L1 antagonist) and paclitaxel + carboplatin chemotherapeutic regimen. The assay output predicted response with chemotherapeutics and degarelix, without any sign of efficacy for PD-L1 antagonist. On the basis of these data, the patient was treated with paclitaxel + carboplatin combination chemotherapy first and showed clinical and radiological response as predicted by the ex vivo platform. After 4 cycles of chemotherapy, the patient received maintenance therapy with degarelix and demonstrated a favorable clinical response. Taken together, our results not only showed the accurate prediction
\end{abstract}

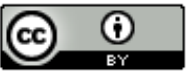

(C) The Author(s) 2020. Open Access This article is licensed under a Creative Commons Attribution 4.0 International License (https://creativecommons.org/licenses/by/4.0/), which permits unrestricted use sharing, adaptation, distribution and reproduction in any medium or format, for any purpose, even commercially, as long as you give appropriate credit to the original author(s) and the source, provide a link to the Creative Commons license, and indicate if changes were made. 
of clinical outcome but also demonstrate the rational selection of a regimen as a viable option for such a clinically challenging disease.

Keywords: Adenoid cystic carcinoma, prostate cancer, chemotherapy, degarelix

\section{INTRODUCTION}

Prostate cancer is the most commonly diagnosed malignancy in men and the second leading cause of cancer death in Western nations ${ }^{[1,2]}$. The pathology of prostate cancer varies with classical adenocarcinoma being the most common histological variant. Small-cell, colloid, mesenchymal and metastatic tumors are the other histological variants ${ }^{[3-5]}$. However, Adenoid cystic carcinoma (ACC) is an unusual histological variant of prostatic carcinoma, that accounts for less than $0.01 \%$ cases $^{[6]}$. Here, we describe the clinical features, morphological spectrum, immunohistochemical (IHC) findings and management option for this unusual subtype of prostatic carcinoma.

\section{Histological features and pathological findings of ACC}

The prostatic epithelium in humans is composed of three major cell types including the secretory epithelial, neuroendocrine and basal cells with the predominance of the secretory epithelial cells ${ }^{[7]}$. These are tall columnar cells containing secretory granules and enzymes that stain for acid phosphatase and prostatespecific antigen (PSA), commonly referred to as glandular epithelium. The neuroendocrine cells that express neuroendocrine markers are present in significant numbers, and the small, round basal cells with little cytoplasm and large irregular nuclei are present in the normal prostate gland. These cells express keratin (types 4,5 and 6 ) and are referred to as pluripotent cells with stem cell-like functions ${ }^{[8]}$.

ACC of the prostate is derived from basal cells (the stem cell compartment of the epithelium) instead of epithelial cells of the ducts and acini ${ }^{[9]}$. The tumor is whitish and comprised of ill-defined, infiltrative edges with involvement of transition and peripheral zones ${ }^{[10]}$. The tumor can have either a predominant basaloid pattern or a cystically dilated acini with cells arranged in cribriform spaces surrounding a eosinophilichyaline basement membrane. The nuclei may be hyperchromatic or micro-vacuolated with angulated nuclear contours. Extensive perineural invasion, extraprostatic extension and desmoplastic or myxoid alterations of the stroma have been described for the tumor ${ }^{[11]}$.

IHC assessment of ACC exhibits high-molecular-weight keratin (clone 34ßE12) and ytokeratin 14 in the majority of cases. Staining for cytokeratin 7 tends to mark an adluminal cell population and basal cell cytokeratin (34ßE12) staining is more frequent in peripheral cells. Staining for cytokeratin 20, p63, and S100 protein has been described in adenoid cystic carcinoma of the prostate with inconsistent results. Scattered chromogranin-positive cells have been reported in these tumors, and the tumor cells are consistently negative for synaptophysin. Elevated Bcl-2 protein and Ki-67 index establishes the extent of proliferation in prostate basal cell lesions. Staining for PSA is usually negative, but some positive cases have been reported, especially in association with concomitant proliferative acinar adenocarcinoma. Additionally, tumor cells have been reported as negative for calponin, smooth muscle myosin heavy chain, and usually smooth muscle actin.

Ho et al $^{[12]}$ sequenced the entire exome or genome in 60 ACC samples and found mutations in cheomatin state regulators (SMARCA2, CREBBP, KDM6A), MYB-NFIB translocations and MYB-associated genes as well as recurrent mutations in the FGF/IGF/PI3K pathway. These findings suggest that ACC carcinogenesis is associated with aberrant epigenetic regulation. Although, ACC originates from the basal cells of prostatic ducts and acini, very little is known about the natural history of the disease owing to the rarity of these 
tumors. The age at presentation has been reported between 28-78 years (mean age of 50 years) with either a normal or slightly elevated serum PSA level ${ }^{[13-16]}$. Due to the slow growing tendency of the ACC of the prostate, the management of patients with advanced and metastatic disease consists primarily of surgical resection followed by periodic long-term follow-up. Use of radiotherapy, chemotherapy and targeted therapies has been reported with inconsistent and varying success ${ }^{[10,15,17,18]}$. Here, we report a case of ACC of the prostate with liver metastasis presented with the dilemma of being a urinary bladder cancer.

\section{CASE REPORT}

A 79-year-old male patient presented with complaints of three episodes of hematuria over a period of 20 days along with generalized weakness without any significant loss of weight or appetite. The patient had a past history of coronary artery disease, type 2 diabetes mellitus, hypertension and chronic kidney disease. The patient had also undergone percutaneous coronary intervention and coronary artery bypass graft in the past. The general condition of the patient was good with an Eastern Cooperative Oncology Group performance status of 1 . The clinical work-up included PSA and magnetic resonance (MR) urography. MR urography was suggestive of mass lesion involving the base of the bladder and prostate. The patient underwent post-transurethral resection of the bladder tumor and prostate. The post-procedure histopathological report showed morphological features of poorly differentiated adenocarcinoma. Metastatic work-up was performed (January 2018) using positron emission tomography-computed tomography (PET-CT) for determination of prostate-specific membrane antigen (PSMA), which showed slightly increased PSMA uptake in the base of urinary bladder and the adjacent prostate along with a large PSMA avid (suv max 8.0) hypodense liver lesion in segment VIII, measuring $8.4 \mathrm{~cm} \times 6.2 \mathrm{~cm}$ [Figure 1]. Post-transurethral resection of the prostate changes were observed with dila ACC of prostate tion of urethra and air pocket along the anterior wall of the urinary bladder. Liver biopsy showed the morphological and IHC features consistent with polymorphic adenoid-basal carcinoma. To understand the histology further, IHC and biochemical evaluation was conducted for multiple markers. CK7 (keratin 7), CD117 (protooncogene c-Kit) and CKHMW (high-molecular-weight cytokeratin) were found to be positive, but PSA, CK20 (keratin 20), NK3 Homeobox 1 (NKX3.1), synaptophysin, chromogranin, and alpha-methylacyl-CoA racemase were negative. Ki-67 proliferation index was 25\%-30\%. In view of CD 117 positivity, the diagnosis of ACC was made; however, the origin of prostate or bladder was still not well defined due to negative PSA. Since, PSA was absent and since the primary bulk of tumor was in the bladder, the possibility of bladder ACC could not be ruled out, albeit a rare entity and never before reported in the literature. There is one report of asynchronous ACC of the prostate and transitional cell carcinoma of the urinary bladder in the literature; therefore, we kept it as a differential diagnosis ${ }^{[19]}$.

PSMA avidity can also be present in poorly differentiated carcinomas irrespective of PSA expression on tumor cells. In view of metastatic disease, we decided to offer chemotherapy to the patient; however, deciding which chemotherapy to offer was still a matter of debate. Based on the clinical differentials, the patient could have been offered either the bladder-based chemotherapy on lines of bladder cancer (gemcitabine + platinum) or docetaxel for prostate origin.

Considering age and co-morbidities, there was only one chance to initiate the appropriate chemotherapy for the patient. In view of the diagnostic dilemma and rare nature of the disease, we decided to perform the CANscript test for the patient. CANscript is a novel phenotypic multi-dimensional assay that tests a patient's tumor tissue against different drug combinations in an ex vivo implant setting to help a physician select the most appropriate treatment protocol. CANscript can predict the response to either singleagent cancer therapeutics or combination therapeutic regimens for the patient under evaluation. This is accomplished by using fresh tumor tissue from the patient in plates coated with a specific set of tumor matrix proteins. Further, patient derived autologous ligands are added to the explant platform along with angiogenic factors and autologous immune cells to maintain the tumor vasculature. In essence, CANscript 

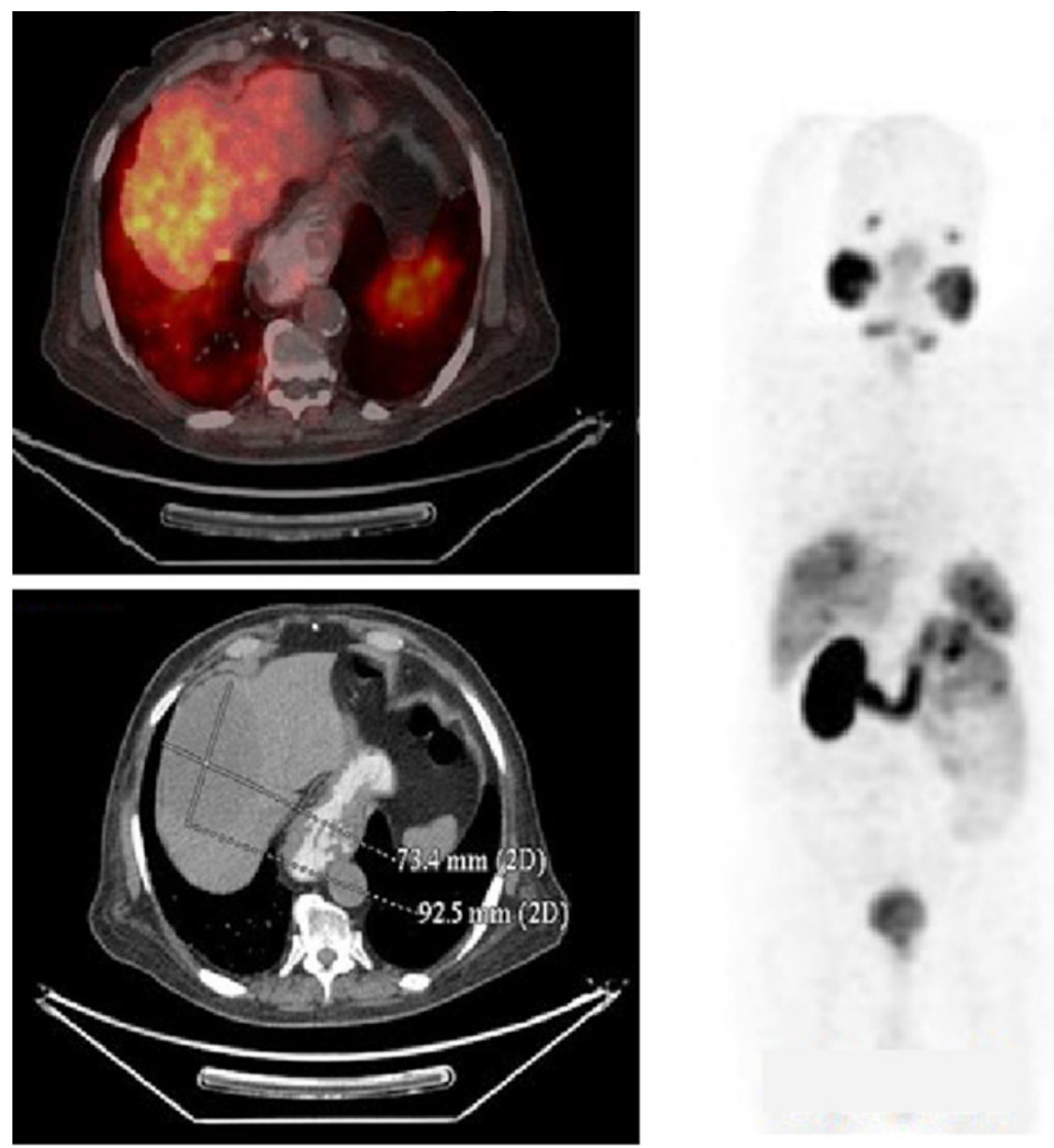

Figure 1. Baseline CT image (January 2018) showing slightly increased prostate-specific membrane antigen (PSMA) uptake in the base of urinary bladder and the adjacent prostate along with a large PSMA avid hypodense liver lesion in segment VIII

recapitulates the tumor microenvironment ex vivo. The sensitivity testing was performed as per the priority list of treatment protocols decided by the attending physician. Option with the highest assigned priority (Tx1) is considered as physician's preferred choice. The test uses a proprietary algorithm to generate an M-score (0-100), with a score of $\leq 25$ predicting non-responders and $\geq 26$ predicting responders ${ }^{[20]}$. Eight treatment arms were tested including drugs commonly used for prostate/bladder cancer, immunotherapy and hormone therapy and the M-score ranged between 3 and 71 with the highest score for Tx1 [Figure 2]. Based on the clinical judgement and the information obtained from the CANscript report, a choice of combination therapy was made, and the patient was started on paclitaxel and carboplatin combination chemotherapy (Tx1) along with androgen deprivation therapy (ADT), degarelix (Tx4). Paclitaxel and carboplatin either alone or in combination with hormonal treatment have been used in the treatment of prostate adenocarcinoma but are not well established for ACC of the prostate. As there was a diagnostic dilemma followed by therapeutic dilemma of prostate $v s$. bladder, a combination of platinum (bladder carcinomas are sensitive to platinums), paclitaxel (approved drug agent for prostate cancer) and $\mathrm{GnRH}$ antagonist (approved for prostate cancer) was used. Post-3 cycles, PET-CT-PSMA demonstrated stable disease. The size of the liver lesion decreased to $8.0 \mathrm{~cm} \times 5.9 \mathrm{~cm}$ along with an increase in necrosis [Figure 3]. Due to poor tolerance, further treatment with chemotherapy was deferred and the patient continued with maintenance on degarelix. PET-CT post-3 months on degarelix showed a slight increase in size of liver lesion with an increase in necrosis [Figure 3]. At present, the patient is alive with good performance status after 16 months (at the time of submission of this manuscript) of follow-up and is on degarelix maintenance therapy. 


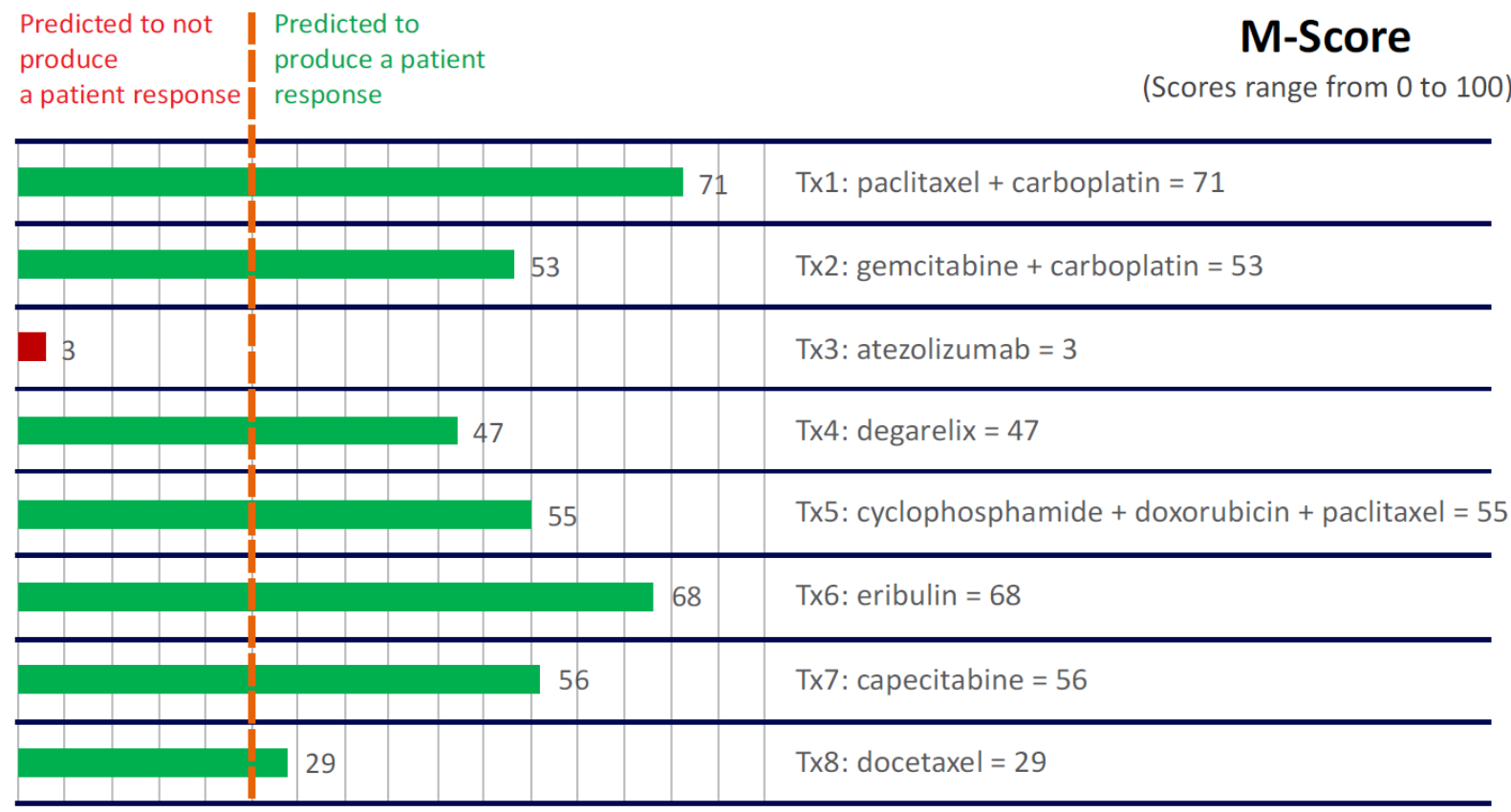

$0 \quad 5 \quad 1015202530 \quad 3540 \quad 4550556065707580$

Figure 2. M-score of eight treatment arms (Tx1 to Tx8) tested on CANscript platform ranging between 3 and 71 with highest score for Tx1

A

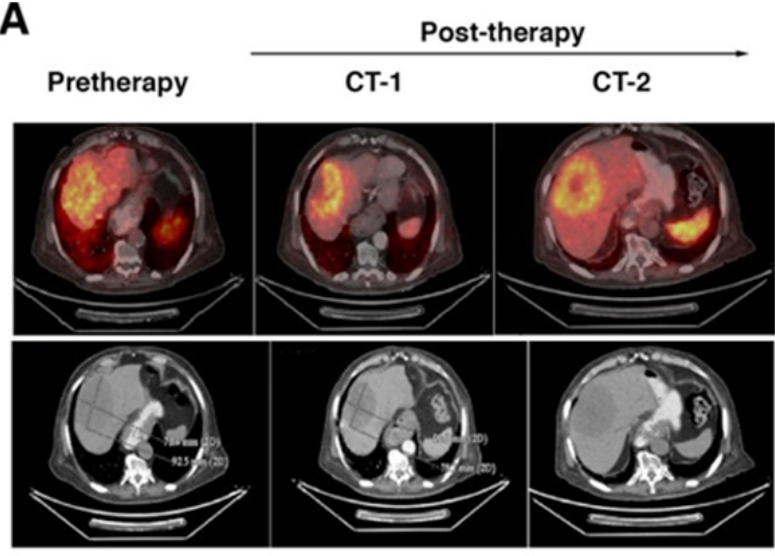

C

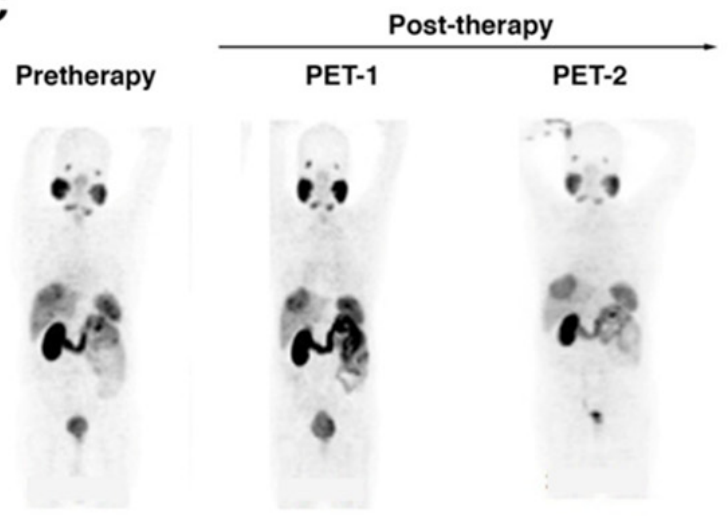

B

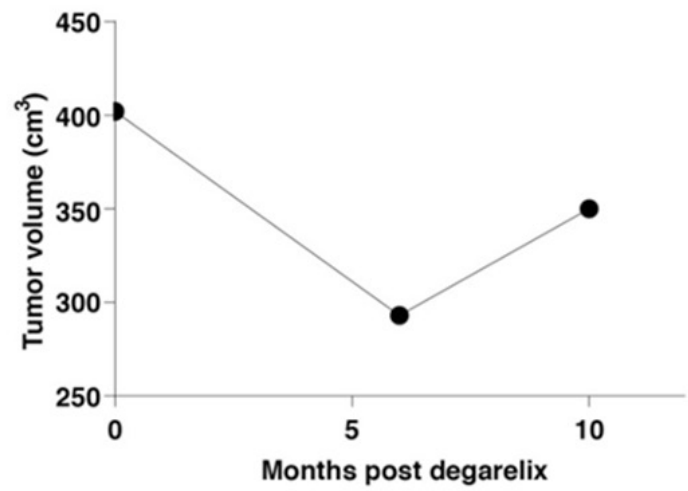

D

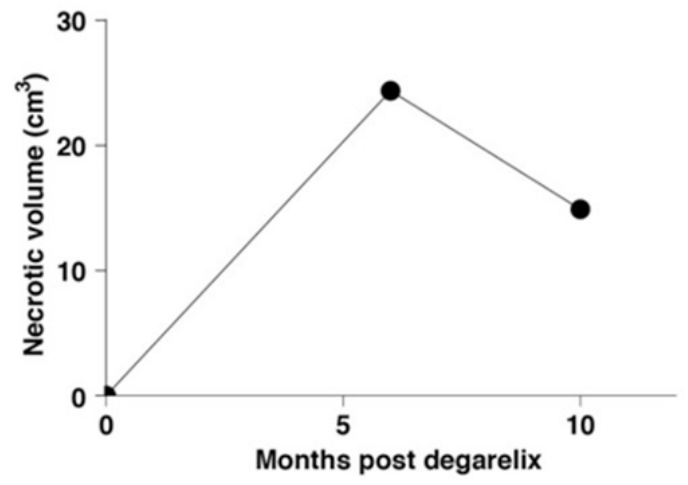

Figure 3. CT image showing the tumor mass at baseline when the case was presented in January 2018, post-degarelix treatment in July 2018 and 7 months post-degarelix treatment in October 2018 (A); graphical representation of the tumor volume (B); PET scan showing decrease in liver lesion with increase in necrosis along with the graphical representation (C and D) 
In view of response to chemotherapy and hormonal treatment, further IHC evaluation of tumor tissue was performed to study the expression profiles of GnRHR, androgen receptor (AR) and immune checkpoint marker PD-L1. Tumor tissue was sectioned at $4 \mu \mathrm{m}$ and stained with hematoxylin/eosin, which revealed prostatic adenocarcinoma [Figure 4A] . Initial baseline IHC evaluation indicated the case to be AR-negative with very low expression of PD-L1 but positive for GnRHR [Figure 4B]. To understand the possible role of GnRHR, we first tested the receptor expression post-treatment with its antagonist degarelix on the CANscript platform. The results indicated that treatment with degarelix decreased the expression of GnRHR-positive cells [Figure 4C]. This retrospective corroboration based on post-treatment response evaluation further confirmed our clinical diagnosis of prostate cancer despite the diagnostic dilemma. Furthermore, bladder cancer does not have these receptors, and prostate cancers are known to be hormone responsive, so the prostate origin of the tumor was further corroborated.

\section{DISCUSSION}

ACC of the prostate is a rare and uncommon malignancy with no well-defined management strategy for the patients with advanced and metastatic disease. ACC of the prostate was first described by Frankel et al. ${ }^{[21]}$ in 1974. Frankel et al. ${ }^{[21]}$ reported a 3-year asymptomatic period for a patient with transurethral resection of the tumor. Iczkowski et al. ${ }^{[13]}$ (2003) reported clinicopathological findings of ACC of the prostate in 19 cases. Of the 19 patients, 5 patients underwent radical prostatectomy, 2 underwent pelvic exenteration, and the rest had no treatment after diagnosis. At a follow-up of 0.3 to 11.8 years, 2 patients died of cancer, 3 remained alive with cancer, and 10 had no evidence of cancer. Schmid et al. ${ }^{[15]}$ (2002) reported a local recurrence in a 44-year-old patient after 7 years of radical prostatectomy and adjuvant radiotherapy, whot was treated with external beam irradiation. After an extended follow-up of more than 9 years, the patient remained asymptomatic with stable disease. McKenney et al ${ }^{[10]}$ (2004) reported a clinicopathological study of 23 cases of basal cell proliferations of the prostate other than usual basal cell hyperplasia, including four carcinomas. Of the 4 carcinoma cases, 1 patient with ACC of the prostate died with extensive metastasis, and the other 3 did not progress at a mean follow-up of 7 years. Unlike these studies that reported ACC of the prostate to be a biologically indolent disease with relatively low risk of distant metastasis, our case demonstrated distant metastasis within 3 weeks of surgical procedure. This not only led to the diagnostic dilemma in the present case but also suggested that ACC of the prostate may be an aggressive disease in some cases. The age at presentation in our case was also higher than the age range reported in previous studies $^{[13]}$. The normal PSA level in our study was consistent with previous reports ${ }^{[14,15]}$.

To the best of our knowledge, only two cases of ACC of the prostate have been reported from India to date. In one of the reports, a 62 -year-old man underwent bilateral orchidectomy after diagnosis followed by hormonal treatment with stable disease in a limited follow-up period of 6 months ${ }^{[22]}$. In the second report, a 68-year-old underwent channel transurethral resection of prostate and bilateral orchidectomy with no new metastasis at a follow-up of 3 years ${ }^{[23]}$. We report the first case of ACC of the prostate treated with paclitaxel and carboplatin-based combination chemotherapy regime along with ADT using CANscript test. It is worthwhile to note that paclitaxel and carboplatin as a combination chemotherapy was never a first choice either for bladder or prostate cancer. The CANscript ex vivo assay lacks the pituitary-testes axis therefore, the luteinizing hormone-releasing hormone (LHRH) antagonist, degarelix is possibly acting directly on the tumor cells. There are few preclinical reports where prostate cancer cell lines have shown response to degarelix ${ }^{[24]}$. The scientific explanation for this is based on the observation that LHRH receptors are present on the surface of the tumor cells thereby contributing to an autocrine response. It is possible the degarelix acts directly on prostate cell growth, as these cells express GnRHR that affects nontumorigenic, hyperplasia-type and tumorigenic cells. This case demonstrates that the CANscript test can assist in resolving the diagnostic dilemma in a rare case of ACC of the prostate. Further, the stable disease along with necrosis achieved in this case establishes the clinical utility of CANscript test in determining the positive prediction of treatment response in rare tumors. 


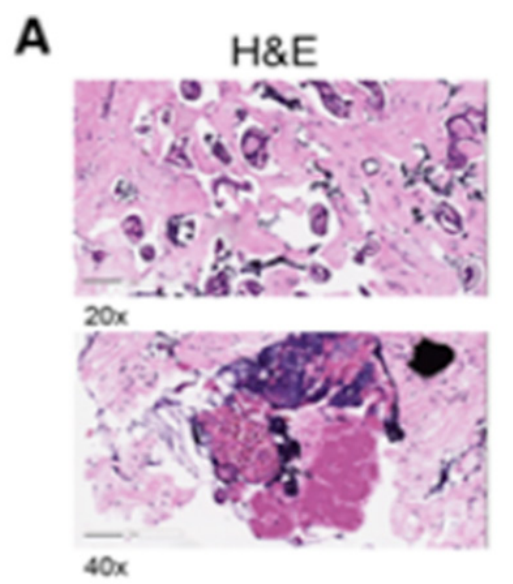

B

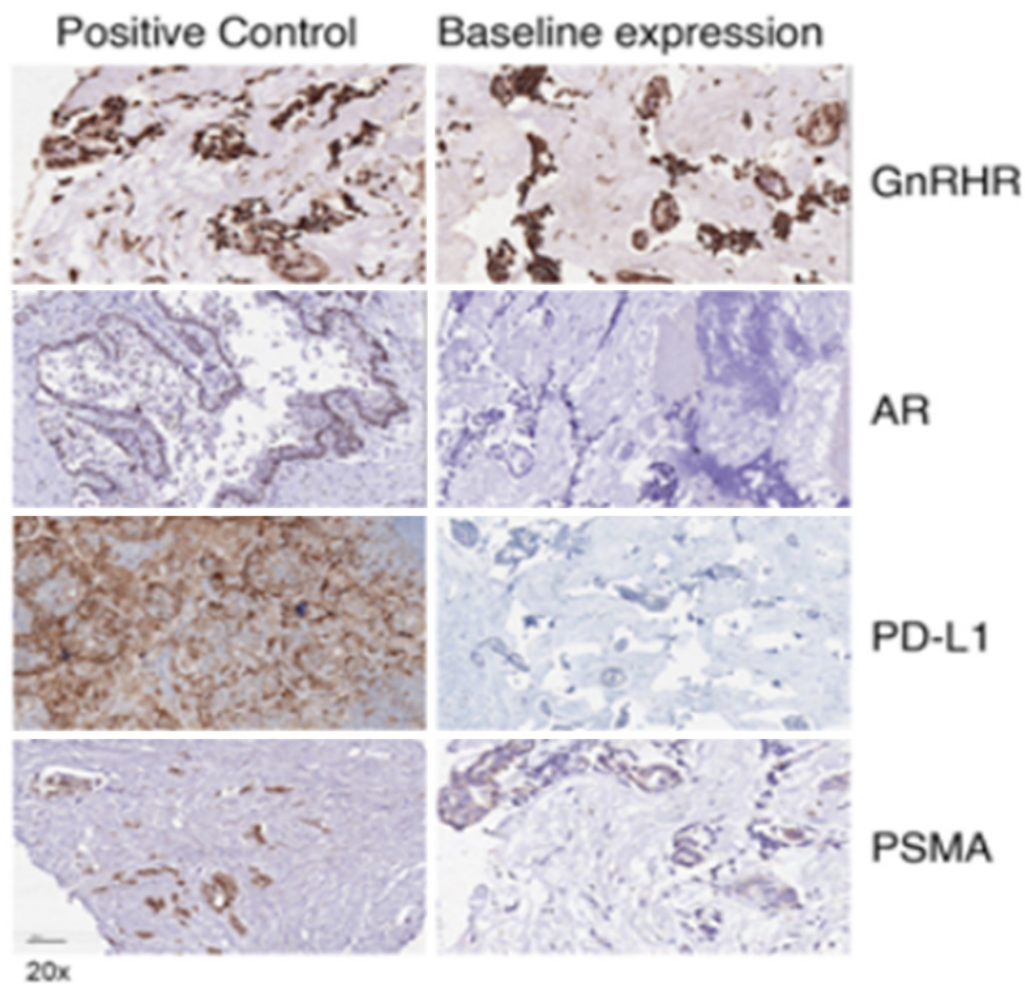

C

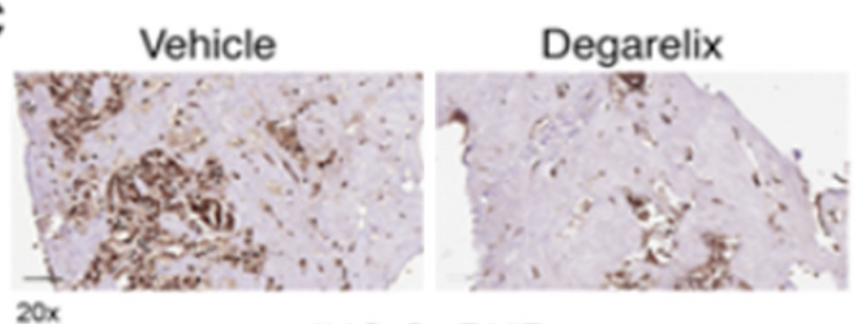

IHC:GnRHR

Figure 4. Hematoxylin and eosin (H\&E) staining for the prostate tumor tissue at 20x and 40x magnification (A); Immunohistochemical images of the indicated markers. Left panel shows the expression of the markers in tissue used as positive control for the expression profile. The right panel shows the expression of the markers in the prostate tumor tissue of the case studied (B); immunohistochemistry of GnRHR in the prostate tumor tissue - at baseline and post-ex vivo degarelix treatment (C) 
In conclusion, ACC is a relatively rare but distinctive tumor in the prostate gland. Infiltrating basaloid cells forming dilated acinar and cribriform spaces with luminal basement like material are characteristic for this tumor. Aggressive findings such as perineural invasion and extraprostatic extension may be found. IHC evaluation shows that the tumor cells are at least focally positive for high-molecular-weight cytokeratin and cytokeratin. Staining for PSA is usually negative, but positivity has been reported. The main differential diagnosis includes benign basal cell hyperplasia and conventional adenocarcinoma with cribriform spaces. Although these tumors have a biological potential that allows metastasis in a few cases, current treatment consists primarily of surgical resection along with close, long-term follow-up. In our case study, we conclude that a novel phenotypic multi-dimensional assay (CANscript) holds the promise to solve the diagnostic dilemma for rare cancers such as ACC of the prostate. Various drug combinations can be tested on the CANscript platform along with an accurate prediction of the treatment response, thereby offering a personalized way of treatment for an individual patient.

\section{DECLARATIONS}

\section{Authors' contributions}

Study concept and design, analysis and interpretation of data, literature search and drafting of the manuscript: Julka PK, Verma A

Critical revision of the manuscript for important intellectual content: Gupta S, Gupta K, Rathod R

Study supervision: Julka PK

\section{Availability of data and materials}

Clinical data and reports supporting the results reported in this article can be found in the patient's medical records.

\section{Financial support and sponsorship}

None.

\section{Conflicts of interest}

All authors declared that there are no conflicts of interest. No benefits in any form have been received or will be received from a commercial party related directly or indirectly to the subject of this article.

\section{Ethical approval and consent to participate}

Ethical approval for the study was not applicable. Subject has given his written informed consent to publish this case (including publication of images).

\section{Consent for publication}

Subject has given his written informed consent to publish this case (including publication of images).

\section{Copyright}

(c) The Author(s) 2020.

\section{REFERENCES}

1. Bray F, Ferlay J, Soerjomataram I, Siegel RL, Torre LA, Jemal A. Global cancer statistics 2018: GLOBOCAN estimates of incidence and mortality worldwide for 36 cancers in 185 countries. CA Cancer J Clin 2018;68:394-424.

2. Ferlay J, Ervik M, Lam F, et al. Global cancer observatory: cancer today. Lyon, France: International Agency for Research on Cancer; 2020. Available from: https://gco.iarc.fr/today/home. [Last accessed on 6 Nov 2020]

3. Moch H, Humphrey PA, Ulbright TM, Reuter VE. WHO Classification of Tumours of the Urinary System and Male Genital Organs. 4. Lyon: IARC Press; 2016. Available from: https://publications.iarc.fr/Book-And-Report-Series/Who-Classification-Of-Tumours/WHOClassification-Of-Tumours-Of-The-Urinary-System-And-Male-Genital-Organs-2016. [Last accessed on 6 Nov 2020]

4. Humphrey PA. Unusual prostatic neoplasms. Prostate pathology. ASCP, Chicago; 2003a. Available from: http://ascpcdn.s3.amazonaws. 
com/static/ASCPResources/Press/store+pdfs/439XTableofContents\%5B1\%5D.pdf. [Last accessed on 6 Nov 2020]

5. Cheville J, Algaba F, Epstein JI, Lopez-Beltran A. Mesenchymal tumours. In WHO classification of tumours of the urinary system and male genital organs. IARC, Lyon, France; 2016. Available from:https://www.yumpu.com/en/document/read/51835534/world-healthorganization-classification-of-tumours-pathology-and-. [Last accessed on 6 Nov 2020]

6. Tannenbaum M. Adenoid cystic or "salivary gland" carcinomas of prostate. Urology 1975;6:238-9.

7. Shen MM, Abate-Shen C. Molecular genetics of prostate cancer: new prospects for old challenges. Genes Dev 2010;24:1967-2000.

8. Rajasekhar VK, Studer L, Gerald W, Socci ND, Scher HI. Tumour-initiating stem-like cells in human prostate cancer exhibit increased NF-kappaB signalling. Nat Commun 2011;2:162.

9. Srigley JR, Dardick I, Hartwick RW, Klotz L. Basal epithelial cells of human prostate gland are not myoepithelial cells: a comparative immunohistochemical and ultrastructural study with the human salivary gland. Am J Pathol 1990;136:957-66.

10. McKenney JK, Amin MB, Srigley JR, et al. Basal cell proliferations of the prostate other than usual basal cell hyperplasia: a clinicopathologic study of 23 cases, including four carcinomas, with a proposed classification. Am J Surg Pathol 2004;28:1289-98.

11. Grignon DJ, Ro JY, Ordonez NG, Ayala AG, Cleary KR. Basal cell hyperplasia, adenoid basal cell tumor, and adenoid cystic carcinoma of the prostate gland: an immunohistochemical study. Hum Pathol 1988;19:1425-33.

12. Ho AS, Kannan K, Roy DM, et al. The mutational landscape of adenoid cystic carcinoma. Nat Genet 2013;45:791-8.

13. Iczkowski KA, Ferguson KL, Grier DD, et al. Adenoid cystic/basal cell carcinoma of the prostate: clinicopathologic findings in 19 cases. Am J Surg Pathol 2003;27:1523-9.

14. Cohen RJ, Goldberg RD, Verhaart MJ, Cohen M. Adenoid cyst-like carcinoma of the prostate gland. Arch Pathol Lab Med 1993;117:799801.

15. Schmid HP, Semjonow A, Eltze E, Wortler K, Hertle L. Late recurrence of adenoid cystic carcinoma of the prostate. Scand J Urol Nephrol 2002;36:158-9.

16. Terris MK. The appearance of adenoid cystic carcinoma of the prostate on transrectal ultrasonography. BJU Int 1999;83:875-6.

17. Jakob JA, Kies MS, Glisson BS, et al. Phase II study of gefitinib in patients with advanced salivary gland cancers. Head Neck 2015;37:644-9.

18. Chau NG, Hotte SJ, Chen EX, et al. A phase II study of sunitinib in recurrent and/or metastatic adenoid cystic carcinoma (ACC) of the salivary glands: current progress and challenges in evaluating molecularly targeted agents in ACC. Ann Oncol 2012;23:1562-70.

19. Fayyad LM, Al-Jader KM, Al-Hawwari BA. Asynchronous adenoid cystic carcinoma of the prostate and transitional cell carcinoma of the urinary bladder. Saudi Med J 2006;27:1060-2.

20. Majumder B, Baraneedharan U, Thiyagarajan S, et al. Predicting clinical response to anticancer drugs using an ex vivo platform that captures tumour heterogeneity. Nat Commun 2015;6:6169.

21. Frankel K, Craig JR. Adenoid cystic carcinoma of the prostate. Report of a case. Am J Clin Pathol 1974;62:639-45.

22. Ahuja A, Das P, Kumar N, Saini AK, Seth A, Ray R. Adenoid cystic carcinoma of the prostate: case report on a rare entity and review of the literature. Pathol Res Pract 2011;207:391-4.

23. Singh SK, Gnanasekharan M, Kumar S, Ganesamoni R, Bal A. Metastatic adenoid cystic carcinoma of prostate: is androgen deprivation therapy beneficial. J Postgrad Med Edu Res 2014;48:43-5.

24. Sakai M, Martinez-Arguelles DB, Patterson NH, Chaurand P, Papadopoulos V. In search of the molecular mechanisms mediating the inhibitory effect of the GnRH antagonist degarelix on human prostate cell growth. PLoS One 2015;10:e120670. 